\title{
CORPO: BRICOLAGE EM BUSCA DA INTERDISCIPLINARIDADE
}

\author{
Cristina Novikoff - UFCG - cristina.novikoff@gmail.com
}

Otávio Barreiros Mithidieri - UNIFOA/UTAD - mithi.koff@globo.com

\begin{abstract}
RESUMO
Ensaio sobre o uso da interdisciplinaridade para se discutir o corpo de modo a ousar a bricolage com ideias de filósofos, sociólogos, psicanalistas, historiadores e educadores. Metodologicamente se adota a perspectiva dimensional da pesquisa acadêmico-científica proposta por Novikoff (2010) a parir de trabalho de doutoramento em andamento na Universidade Trás-os-Montes (UTAD), com orientação do Laboratório do Grupo de Estudos e Pesquisas em Representações Sociais na/para Formação de Professores credenciado na Universidade Federal de Campina Grande (LAGERES- UFCG). A proposta objetiva apresentar a discussão sobre corpo dentro da revisão conceitual e de seus fundamentos, para pensar os lugares e as representações sociais de corpo.
\end{abstract}

PALAVRAS-CHAVE: corpo/ser; interdisciplinaridade; representações sociais.

\section{BODY: BRICOLAGE IN SEARCH OF INTERDISCIPLINARITY ABSTRACT}

Essay on the use of interdisciplinarity to discuss the body in order to dare the DIY with ideas from philosophers, sociologists, psychoanalysts, historians and educators. Methodologically, one adopts the dimensional perspective of the academic-scientific research proposed by Novikoff (2010) to take on PhD work in progress at Universidade Trás-os-Montes (UTAD), with guidance from the Laboratory of the Group of Studies and Research in Social Representations in / For Teacher Training accredited at the Federal University of Campina Grande (LAGERES- UFCG). The proposal aims to present the discussion about body within the conceptual revision and its foundations, to think about places and social representations of body.

KEY WORDS: body / being; Interdisciplinarity; Social representations..

\section{CUERPO: BRICOLAJE EN BÚSQUEDA DE INTERDISCIPLINARIDAD RESUMEN}

Ensayo sobre el uso de la interdisciplinariedad para discutir el cuerpo de modo a atreverse al bricolaje con ideas de filósofos, sociólogos, psicoanalistas, historiadores y educadores. Se adopta la perspectiva dimensional de la investigación académica-científica propuesta por Novikoff (2010) a parir de trabajo de doctorado en curso en la Universidad Trás-os-Montes (UTAD), con orientación del Laboratorio del Grupo de Estudios e Investigaciones en Representaciones Sociales Para la Formación de Profesores acreditados en la Universidad Federal de Campina Grande (LAGERES- UFCG). La propuesta objetiva presentar la 
discusión sobre el cuerpo dentro de la revisión conceptual y de sus fundamentos, para pensar los lugares y las representaciones sociales de cuerpo.

PALABRAS CLAVE: cuerpo / ser; Interdisciplinariedad; Representaciones sociales.

\section{INTRODUÇÃO}

$\mathrm{Na}$ perspectiva de Latour (2000, 1979), que reorganiza o cenário das ciências descrevendo a heterogeneidade como elemento de conexões entre elementos díspares, o Laboratório do Grupo de Estudos e Pesquisas em Representações Sociais na/para Formação de Professores credenciado na Universidade Federal de Campina Grande - LAGERES/CNPq - criado em 2010 - ousa confrontar seus objetos de estudos transversalizados pela Teoria das Representações Sociais- TRS e experimentá-los na triangulação teórico-epistemológica e metodologicamente, de modo a vivenciar a interdisciplinaridade.

Se historicamente a linearidade desde a modernidade para o mundo ocidental marcou as ciências com sua visão mecanicista a partir da ideia de que a mesma lógica que explica os tempos e os espaços da natureza pode explicar os tempos e os espaços do homem, e a epistemologia de corpo, a filosofia pós-moderna rompe e permite outros olhares sobre esse objeto/ser.

Se antes os corpos eram representados na arte distorcidamente, como por exemplo, as crianças pintadas como adultos em miniaturas, mulheres sempre frágeis e homens como representação da força (CORBIN, COUTINE; VIGARELLO, 2008), em que o tempo e espaço entendidos como categorias racionalizáveis, que se movem em perspectivas lineares e, por isso, passíveis de algum controle, Foucault (1995) rompe e desconstrói tal entendimento.

A perspectiva rizomática rasga a disjunção entre a natureza e a sociedade e Latour (2000, 1979) demonstra além de tal ruptura a relação entre o dispositivo experimental e a rivalidade entre filósofos, permitindo confrontar o político e o experimentalista.

Tais procedimentos (in)juntivos traz para o campo das ciências uma heterogeneidade de elementos e (des) conexões que extrapolam as delimitações epistemológicas entre o que é da ordem do conhecimento e o que não é. A produção se faz via bricolage, ou seja, (des) (re) construções conceituais para dar conta do tempo presente.

Eis o desafio ao se estudar corpo/ser na atualidade a que nos propusemos nesse ensaio. 


\section{NOÇÕES SOBRE REPRESENTAÇÕES SOCIAIS}

Em 1961 é publicada a obra que incomodaria os franceses tanto em sua organização científica de se pensar e fazer ciências segmentando o objeto cientifico do senso comum, bem como a ideia de que os franceses compreendiam bem a psicanálise. $\mathrm{O}$ romeno naturalizado francês expõe sua teoria denominada de Teoria das Representações Sociais (TRS) em sua obra intitulada La Psychanalyse: son image et son public. Ela é considerada uma forma sociológica da Psicologia Social em que trata o pensamento constituído nas relações sociais.

Moscovici $(1978,2010)$ pontuou toda representação como sendo uma representação de alguma coisa e são espalhadas/instituídas em todos os campos de saberes, inclusive na academia no meio de cientistas.

Sandra Jovchelovitch (1995) revisa a TRS para clarear seu surgimento e sua condição no final da década de noventa. Sua importância histórica, de acordo com a pesquisadora, foi em demarcar o cenário de interrogações radicais cercado de contradições e dilemas que careciam de respostas tanto sob o auspicio da teoria como da metodologia sobre a subjetividade em indivíduos e sociedade. E entre as contradições ressaltou a importância de se esclarecer sobre a relação indivíduo-sociedade e como esta relação se constrói.

Se de um lado sofremos os equívocos de uma compreensão demasiado individualizante, psicologista nos seus parâmetros de compreensão da subjetividade, por outro, muitas vezes as tentativas de introduzir conceitos sociológicos à Psicologia Social sucumbiram à tentação maniqueísta do inverso. Assim, ou ficávamos no individual fechado no âmbito de um Eu abstraído do mundo que o constrói, ou travávamos a sociedade e a história como abstração. Uma sociedade sem sujeitos ou sujeitos sem uma história social são parte de problemas que todos nós conhecemos muito bem - e recuperar essa conexão é uma das tarefas cruciais que temos pela frente. (p. 63)

Jodelet (2001, p. 22) organiza uma apresentação elucidativa sobre as representações sociais e passa a ser largamente adotada entre os teóricos que se debruçam sobre a TRS:

é uma forma de conhecimento, socialmente elaborada e compartilhada, com um objetivo prático, e que contribui para a construção de uma realidade comum a um conjunto social. Igualmente designado como saber de senso comum ou ainda saber ingênuo, natural, essa forma de conhecimento é diferenciada entre outras do conhecimento científico. Entretanto, é tida como 
um objeto de estudo tão legítimo quanto este devido à sua importância na vida social e à elucidação possibilitadora dos processos cognitivos e das interações sociais.

As representações sociais, assim entendidas, como conhecimento do sujeito sobre mundo, coisas, o outro, a ciência, são comunicadas de modo singular e com a função de tornar o não-familiar em algo familiar.

Palmonari e Cerrato (2011) esclarecem que os pensamentos, sentimentos e motivações se imbricam e que a psicologia social passa a observá-los não mais com base na análise individual, mas sim na perspectiva da sociedade onde se vivencia o processo de interação com os outros como fazem a antropologia, sociologia e economia.

Em linhas gerais o conceito de representações individuais e representações coletivas, historicamente eram dados como dicotomia, até que Moscovici $(1978,2010)$ iniciou seus estudos sobre as representações sociais e demonstra o impacto das interações na constituição de representações sociais. Enquanto ancorar é o processo que permite familiarizar com o pensamento implícito, a objetivação significa materializar as significações. É a cristalização de uma representação que nos remete a este processo.

Para se entender um pouco mais sobre esse fenômeno da configuração das representações sociais, Moscovici $(1978,2010)$ esclarece que ela ocorre por meio de dois processos imbricados, ou seja, objetivação e ancoragem. $\mathrm{O}$ primeiro tem a qualidade de transformar entes imaginários e ideias em objetos quase "tangíveis" ou "tocáveis", em razão da materialização operada pela mente em seu processo de apreensão do mundo.

Este processo, por sua vez implica três etapas: inicialmente, descontextualiza-se a informação através de critérios normativos e culturais, em seguida, forma-se uma estrutura que reproduz de maneira figurativa uma estrutura conceitual. A última etapa é a naturalização, momento em que as imagens são transformadas em elementos da realidade.

O segundo processo das representações sociais em seu aspecto sociocognitivo do fenômeno (intra, inter, trans) subjetivo é denominado de ancoragem e tem por objetivo "ancorar" ou "alocar" o novo conhecimento em categorias/esquemas cognitivos comuns ao sujeito, podendo esse ser renovado ou transformados em esquemas/categorias, gerando novos esquemas/categorias (TRINDADE, SANTOS, \& ALMEIDA, 2011; MOSCOVICI, 2003, SPINK, 1993). 
A abordagem sociocognitiva apresentada anteriormente é enriquecida quando se discute o fenômeno das representações sociais como sendo, também um fenômeno das emoções, portanto, socioafetivos. E, dela Guareschi e Jovchelovitch (1995) apresentam três dimensões sendo o caráter simbólico e imaginativo acrescidos da dimensão dos afetos, esclarecendo o lugar desses nos processos de dar sentido ao mundo e de se relacionarem com os outros e a si mesmos. A emoção da construção do conhecimento, de pertencer e, enfim, de dar significação simbólica é, simultaneamente, um ato de conhecimento e um ato afetivo.

Pode-se concluir, portanto, que as representações sociais não podem ser reduzidas apenas ao cognitivo, já que são estruturas cognitivo-afetivas vistas como formas de conhecimento prático instituído na interação, no espaço relacional, com cognição, valores e emoção.

\section{INTERDISCIPLINARIDADE(S)}

O termo interdisciplinaridade foi explorado nas áreas do conhecimento da educação, saúde, filosofia, sociologia e história, como se falassem de uma única perspectiva. Aqui propomos trazê-lo no seu plural pela polifonia e polimorfismo que o cerca.

Sem revisitar os termos já explorados sobre inter, multi, pluri, trans (disciplinaridade) o que propomos aqui é outra abordagem - a da totalidade concreta na perspectiva de Kosik (1978). Noutras palavras, não é tudo e nem é a busca do princípio fundador de tudo. Investigar dentro da concepção da totalidade concreta significa buscar explicitar, de um objeto de pesquisa delimitado, as múltiplas determinações e mediações históricas que o constitui. A historicidade dos fatos sociais consiste fundamentalmente na explicitação da multiplicidade de determinações fundamentais e secundárias que os produzem.

A interdisciplinaridade, nesse lugar, é pensada a partir de vários autores que a têm discutido. E, ao contextualizar o surgimento da interdisciplinaridade retomamos, na literatura brasileira os anos setenta, especialmente de Japiassu e Fazenda que se respaldaram no trabalho de Gusdorf $(1974,1977)$. A abordagem, portanto foi humanista e idealista (ALVES; BRASILEIRO; BRITO, 2004) .

Japiassú (1976), tratou a interdisciplinaridade na sua obra intitulada "Interdisciplinaridade e Patologia do Saber", descontruindo a ideia de epistemologia centrada 
na filosofia e desloca para o campo da construção de novas propostas centradas em experiências sobre o método do trabalho interdisciplinar. $\mathrm{Na}$ sua elaboração caracteriza a interdisciplinaridade pelo grau de integração real das disciplinas no interior de um mesmo projeto de pesquisa e pela intensidade das trocas entre os especialistas.

Fazenda (1991), centrada na ideia humanista e pautada no mesmo pressuposto de Japiassú valora o exercício interdisciplinar para a ampliação do conhecimento e defende que a fragmentação do saber fragiliza a intervenção profissional e acentua a atitude interdisciplinar, norteada pela reciprocidade, troca, diálogo entre pares idênticos, anônimos ou consigo mesmo, além da humildade perante as limitações do próprio saber e a perplexidade perante as descobertas de novos saberes.

Minayo (1994) adentra na discussão com sua obra "Interdisciplinaridade: funcionalidade ou utopia?" para propor outros entendimentos de interdisciplinaridade. Apresenta a proposta de Carneiro Leão que coloca em suspenso o potencial transformador e pretensamente crítico da visão humanista de interdisciplinaridade defendido por Gusdorf (1976), que acabou sendo apenas um novo modo de nomear, mas com as mesmas práticas de construção do conhecimento. Acusa, então, a perspectiva humanista de apontar uma interdisciplinaridade de retóricas de persuasão que implica, no mais claro servilismo ao caráter funcionalista da ciência.

É com Ely (2003) que se se revisa a década de 90 e as contradições nos estudos ditos interdisciplinares que acabam por ser fonte de modismos sem sustentação teóricometodológica.

Tonet (2013) contribui e enriquece a discussão ao apresentar a critica de que os teóricos apresentam fundamentos da proposta da interdisciplinaridade como "uma solução equivocada para um problema mal equacionado"(p.5). Segundo o autor, a teoria da interdisciplinaridade, não tem como ponto de partida uma teoria da fragmentação, apenas reconhece as consequências negativas de tal.

Deixando de lado as raízes materiais da fragmentação do conhecimento, e mesmo admitindo que este é um processo natural, pressupõe que se trate de um problema meramente epistêmico e que, portanto, pode ser superado também no plano epistêmico. Quando muito, além desse plano meramente epistêmico também se agrega um plano moralista, enfatizando a necessidade de ter atitudes pedagógicas integradoras. (TONET, 2009, pg.735) 


\section{ORIENTAÇÕES COMPORTAMENTAIS E REPRESENTAÇÕES SOCIAIS DE CORPO}

O corpo na perspectiva interdisciplinar, tomando essa como processo de encontros e desencontros vem fundamentado na TRS é o instrumento conceitual proposto no presente tópico. Vale pontuar que o simbólico, como apresentado, anteriormente, materializa o pensamento em seu aspecto contivo e afetivo. Cabe acrescer o conceito de imaginário como magma que tem força criadora do próprio simbólico, como nos elucidou Castoriadis (1982, 1987).

A questão sobre como o corpo enquanto objeto é vizivel nas artes, nas ciências, na literaratura entre outros espaços em que a mente é separada do corpo e fixa-se a sua dicotomia até Spinoza propor outra abordagem mais integrativa.

A proposta do exercício intelectual para pensar o corpo-ser nasce de debates rígidos entre pares conscientemente de nosso imaginário radical. Vale ressaltar que apesar de nosso materialismo histórico, apontamos que se a ideia de Marx e Engels (2007, p. 37) de que "não é a consciência dos homens que determina o seu ser, mas, ao contrário, é o seu ser social que determina a sua consciência" se materializasse, bastava que as escolas discutissem a teoria marxista como fazem as universidades brasileiras para se revelar uma sociedade diferente da capitalista.

Na realidade isso não ocorre linearmente. As relações sociais de produção tem força de determinação no nosso modo de ser e pensar, mas não determinam. Castoriadis (1982) já nos aclarou sobre o outro elemento que não a lógica - o imaginário, guarda a capacidade de utilizar, mas, também de criar o simbólico. Para esse filósofo, o imaginário além de utilizar o simbólico, não somente para se exprimir, o faz para existir e, inversamente, o simbólico pressupõe a capacidade imaginária de evocar uma imagem: "ver uma coisa que ela não é, de vê-la diferente do que é. O imaginário é obra de uma imaginação radical, não especular, permanente.(CASTORIADIS, 1982, p.154).

Este imaginário é ao mesmo tempo duplo (social- como rio aberto do coletivo anônimo, histórico e como psique-soma psíquico- fluxo representativo/afetivo/intencional) e irresolvível. Ambos dependem da lógica dos magmas onde, qualquer que seja o esforço de racionalidade, o resíduo inexplicável permanece um magma, dinamizado por um fluxo 
incessante de representações, concebidas como expressões de uma imaginação radical e não como reflexo ou cópia de algo.

Nessa perspectiva que se lê e interpreta e explica-se o quão representado socialmente é o corpo como elemento/objeto que ora serve de referente para as artes, ciências, história, sociologia, psicologia, educação, entre outras áreas de conhecimento. Cabe lembrar que desde o idealismo de Sócrates e de Platão passando pelo cristianismo e transitando pelo dualismo de res cogitans e res extensa, de Descartes, o corpo foi separado da mente. Em Descarte (1999), o sujeito - mente - é isolado dos sentidos, e o conhecimento verdadeiro, por sua vez, consistirá justamente na separação da alma e do corpo. Segue Descartes (1999) que além de separar hierarquiza a extensão - res extensa - e o pensamento - res cogitans - , privilegiando a mente em detrimento do corpo.

Spinoza (2009) rompe essa corrente disjuntiva com o amalgama afeto, ou seja, "por afeto compreendo as afecções ${ }^{1}$ do corpo, pelas quais sua potência de agir é aumentada ou diminuída, estimulada ou refreada, e, ao mesmo tempo, as ideias dessas afecções" (SPINOZA, 2009, p.163).

Os corpos, ao se encontrarem possibilita a ocorrência do que o filósofo define como a afecção que pode ser dada por três afecções primárias: (i) alegria - conatus $^{2}$ aumentado; (ii) tristeza - conatus diminuído; e (iii) desejo ${ }^{3}$ - conatus. Dessas outras nascem, como raiva, apatia, aversão e etc.

Os encontros dos corpos sofrem constrangimentos ou expansões de potência que são expressos na mente por meio das ideias. Essa é a dimensão afetiva da experiência, pois o afeto é entendido por Spinoza (2009) como "a ideia de uma afecção do corpo" (SPINOZA, 2009, p. 98). Há uma variação em paralelo da potência de agir e de pensar.

${ }^{1}$ Afecção é "a modificação de um corpo causado pelo encontro com outro corpo" (SPINOZA, 2009, p. $111)$.

${ }^{2}$ De acordo com Spinoza (2009), o conatus é a essência de todo corpo, isto é, aquilo sem o qual uma coisa não pode existir e, sequer, ser concebida. Logo, sem o conatus, um corpo não pode existir e ser concebido. Portanto, o conatus, enquanto essência do corpo, é a força do corpo para continuar em sua existência, ou seja, continuar sendo o que é, afirmando sua existência e as relações que o compõem.

3 “O desejo é a própria essência do homem, isto é, o esforço pelo qual o homem se esforça por preservar em seu ser" (SPINOZA, 2009, p. 168). 
Com as noções de afetos e potências Spinoza propõe a existência de dois modos de vida: (i) a vida do homem passivo, que vive entregue a seus encontros e nada faz para orientálos de forma a experimentar mais tristezas que alegrias; e (ii) a vida do homem ativo, que, pelo esforço da razão, busca orientar seus encontros de forma a experimentar mais alegrias do que tristezas. Por esses dois tipos de vida, percebe-se que a alegria está vinculada à ação e à liberdade, ao passo que a tristeza está vinculada à servidão e á paixão (DELEUZE, 2002).

Nas representações imagéticas da atualidade os corpos tendem a ser delineados por normativas corporais para atender a sociedade de consumo, similar ao já demonstrado por Foucault (1987) ao descrever os corpos controlados e corpos dóceis pautando-se na análise de instituições que com suas normativas e punições impõe formas de ser e estar.

As diferentes estratégias pensadas, calculadas são manifestas na corporeidade, ou seja, atinge a alma de tal modo a diminuir a potência de agir do sujeito. Tal controle do corpo enquanto meio de atingir a alma se deu mediante a capilarização dos poderes individuais, medidas econômicas e judiciárias entre outras visibilizadas na atualidade por diversos meios de comunicação, legislação educacional, pauta econômico-financeira, cultos religiosos, e diferentes instituições, que aqui não há espaço para alargar o tema.

\section{ALGUMAS PALAVRAS DE ENCERRAMENTO}

O corpo-ser é uma alternativa para provocar o imaginário frente as determinações das produções de conhecimento, em especial quando estas são revestidas de representações sociais.

As representações sociais de corpo nasce na espacialidade e temporalidade dos processos de aprendizagem que se diferem da espacialidade e da temporalidade formal e cronológica que orienta e define o ritmo da sociedade e da natureza. Dai pontuar algumas ideias provocativas para futuras discussões:

$\checkmark$ As representações sociais de corpo ao longo da história carrega em si o caráter simbólico e imaginativo configurado por uma dimensão dos afetos com força de determinação, mas não determinante em si. 
$\checkmark$ Os tempos e os espaços da aprendizagem sobre o corpo têm mais a ver com os ritmos não lineares da subjetividade e com os significados das experiências humanas e seus afetos do que com a adequação aos padrões formal e previamente determinados, como querem assinalar as correntes idealistas como as materialistas.

$\checkmark$ O corpo e suas representações ontologicamente vêm se dando num movimento aleatório, inesperado e expressivo da existência, não apreendido pelo planejamento racional, porque é imprevisível. Nem a sociedade de consumo consegue a hegemonia corporal.

Com tais proposições, assinalamos que no âmbito da aprendizagem sobre o corpo de si e do outro, o tempo que transcende o kronos é o kairós - o das relações com o tempo das vivências que dá significado aos acontecimentos/encontros e desencontros. Só o tempo vivência atravessa a temporalidade cotidiana que configura o corpo em corpo-ser/estar.

E corpo assim, ser/estar é criação, é o espaço, que transcende o "físico", é o que se converte em "dimensão" com seus significados, representações, valores e estímulos que colocam ativos ou passivos diante do mundo e das coisas.

\section{REFERÊNCIAS BIBLIOGRÁFICAS}

CASTORIADIS, Cornelius. A instituição imaginária da sociedade. Rio de Janeiro: Paz e Terra, 1982.

Psicanálise e sociedade II. In: As encruzilhadas do labirinto / 2. Os domínios do

Homem. Rio de Janeiro: Paz e Terra, 1987.

DELEUZE, Gilles. Spinoza: filosofia prática. São Paulo: Escuta, 2002.

FAZENDA, Ivani. Interdisciplinaridade: História, teoria e pesquisa. Campinas: Papirus, 1991.

FOUCAULT, Michel. Vigiar e punir: nascimento da prisão. 5. ed. Petrópolis: Vozes. 1987. GUARESCHI, P.; JOVCHELOVITCH, S. (Org.). Textos em representações sociais. 2. ed. Petrópolis: Vozes, 1995.

GUSDORF, Georges. Prefácio. In JAPIASSÚ, Hilton. Interdisciplinaridade e patologia do saber. Rio de Janeiro: Imago, 1976. 
JODELET, D. (Org.) As Representações Sociais. Rio de Janeiro: EdUERJ. 2001.

JOVCHELOVITCH, S. Vivendo a vida com os outros: intersubjetividade, espaço público e representações sociais. In: GUARESCHI, P. A. \& JOCVHELICTCH, S. Textos em Representações Sociais. 2ed. Petrópolis, RJ: Vozes, 1995

LATOUR, Bruno. Ciencia em ação: como seguir dentistas e engenheiros sociedade afora. São Paulo. Editora UNESp, 2000.

MOSCOVICI, S. A Representação Social sobre a Psicanálise. Rio de janeiro: Zahar Editores, 1978.

MOSCOVICI, S. Representações Sociais: investigações em psicologia social. Petrópolis: Ed.:Vozes, 2010.

NOVIKOFF, C. As Representações Sociais Acerca do Ensino Superior para professores de graduação na área da saúde. Tese (Doutorado em Educação: Psicologia da Educação), São Paulo: Pontifícia Universidade Católica de São Paulo, 2006.

NOVIKOFF, C. Dimensões Novikoff: um constructo para o ensino-aprendizado da pesquisa. In: ROCHA, J.G. e NOVIKOFF, C. (orgs.). Desafios da práxis educacional à promoção humana na contemporaneidade. .Rio de Janeiro: Espalhafato Comunicação, p. 211-242, 2010.

PALMONARI, A. \& CERRATO, J. Representações sociais e psicologia social. In: Teoria das representações sociais: 50 anos. ALMEIDA, Angela Maria de Oliveira, SANTOS, Maria de Fátima de Souza e TRINDADE, Zeidi Araujo (org). Brasília: Technopolitik. Co-edição: Centro Moscovici/ UnB, 2011.

TONET, Ivo. Interdisciplinaridade, formação humana e emancipação humana. Serv. Soc. Soc., São Paulo, n. 116, p. 725-742, Dec. 2013. Disponível em: < http://www.scielo.br/scielo.php?script=sci_arttext\&pid=S0101-66282013000400008 >. Acesso em: 05 jun. 2017.

SPINOZA, Benedictus de. Ética. Belo Horizonte: Autêntica, 2009.

TONET, Ivo. Marxismo para o século XXI. Em defesa do futuro. Maceió: Edufal, 2005. 